Gazi University
Journal of Science
http://dergipark.gov.tr/gujs

\title{
The Role of Annealing on The Structural, Optical and Electrical Properties of Au-Copper Oxide Films Deposited by Chemical Bath Deposition
}

\author{
Emine GUNERI ${ }^{1, *}$ (iD) \\ ${ }^{1}$ Education Faculty, Erciyes University, 38039, Kayseri, Turkey
}

\begin{tabular}{l} 
Article Info \\
\hline Received: $17 / 10 / 2018$ \\
Accepted: $20 / 06 / 2019$ \\
Keywords \\
\hline Au-CuO \\
Annealing effect \\
Thin film
\end{tabular}

\begin{abstract}
In this work, the effect of annealing on $\mathrm{Au}-\mathrm{CuO}$ films obtained by chemical bath deposition method was studied in terms of their structural, electrical and optical properties. Annealing process was carried out at an oxygen environment. The $\mathrm{CuO}$ peaks were detected using $\mathrm{X}$-ray diffraction and all of the films were polycrystalline. Crystal size, preferential orientation, and surface tension were estimated from XRD data. The surface morphology and thickness of the films was determined using a field emission scanning electron microscope. Energy dispersive Xray analysis stated average atomic percentages of $\mathrm{Au}$ in the films. The electrical resistivity values of the films determined using four probe methods varied from 155.74 to $496.87 \Omega$.cm. The optical properties of the films were determined using the optic spectrometer. The energy band gap values, extinction coefficient, refractive index and dielectric coefficient of the films were also calculated.
\end{abstract}

\section{INTRODUCTION}

In the past decades, the researchers focus on cupric oxide $(\mathrm{CuO})$ due to environmental suitability, low-cost production, easily-formed and thermodynamically stable [1-3]. According to the results of research, $\mathrm{CuO}$ thin film can be used in gas sensor [4], solar cell [5], lithium cell [6], and so on. To fabricate $\mathrm{CuO}$ thin film, there are different methods such as RF magnetron sputtering [7], chemical spray pyrolysis [8], successive ionic layer adsorption [9], and chemical bath deposition (CBD) [10]. In this work, CBD is used due to the simple requirement, and reproducibility [11-12]. To change the structural, electronic and optical properties of $\mathrm{CuO}$ thin films, researchers either annealing or doped [13-18]. So, they added different features to $\mathrm{CuO}$. For example, $\mathrm{Au}$ was doped to $\mathrm{CuO}$ films to detect gases by Ando et al [19] and Proença et al [20]. The $\mathrm{CuO}$ films were annealed at a different temperature to fabricate the photovoltaic device, sensor, by Marzukil et al [13] and Gopalakrishana et al [14]. In this work, it was examined how the structural, optical and electrical properties of $\mathrm{Au}-\mathrm{CuO}$ films changed with annealing.

\section{EXPERIMENTAL DETAILS}

The $\mathrm{Au}-\mathrm{CuO}$ films were deposited on glass substrates by using chemical bath deposition. The glass substrates were cleaned using acetone, ethanol, isopropyl alcohol, followed by rinsing with double distilled water. $\mathrm{Cu}(20-40 \mathrm{~nm})$ and $\mathrm{Au}(5 \mathrm{~nm})$ nanoparticles were purchased from Alfa Aesar and Aldrich, respectively. The solution containing $\mathrm{Cu}$ nanoparticles was prepared with a mixed solvent comprised of ethylene glycol $(10 \mathrm{ml})$, ethanol $(10 \mathrm{ml})$ and DI water $(10 \mathrm{ml}) .0 .07 \mathrm{gr}$ of $\mathrm{Cu}$ nanoparticles were added to the pre-mixed solvents. It was stirred vigorously and to appear homogeneous and dark green in color. After that Au nanoparticle becoming different ratio $(0-500 \mu \mathrm{l})$ added to solution. The solution was stirred by an ultrasonic bath for $20 \mathrm{~min}$. The color of solution didn't change. After vigorous stirring, substrates were placed in the solution and experimental process was carried out in the oven at $80^{\circ} \mathrm{C}$ for $5 \mathrm{~h}$. The films were then dried at room temperature for $24 \mathrm{~h}$ then annealed in an oxygen environment at $500{ }^{\circ} \mathrm{C}$ for $1 \mathrm{~h}$. The structural properties of the films were investigated by X-ray diffraction (XRD; Rigaku SmartLab.) with Cu- 
$\mathrm{K} \alpha$ radiation $\left(\lambda=1.54178 \AA\right.$ ) in the $2 \theta$ range of $30-90^{\circ}$ with $3.02^{\circ} / \mathrm{min}$ scanning speed. Crystalline phases were determined using the Joint Committee of Powder Diffraction Standards (JCPDS) files. The morphology structure and elemental composition of $\mathrm{Au}-\mathrm{CuO}$ films were investigated with a Zeiss Gemini 500 filed emission scanning electron microscopy (FESEM), attached with energy dispersive spectroscopy (EDX). To determine the electrical properties, the home-made four probe system was used. The optical properties of films were obtained with a double beam spectrophotometer Perkin-Elmer Lambda 25 at room temperature, taking air as reference.

\section{RESULTS AND DISCUSSION}

\subsection{Structural Properties of Au-CuO Films}

The XRD patterns of the obtained films were investigated to analyze changes in the composition. According to XRD data in Figure 1, there is $\mathrm{CuO}$ monoclinic structure ( $\mathrm{PDF}=1011194)$ in the structure. In the films, no $\mathrm{Au}$ nanoparticles were observed in the XRD pattern (Figure 1). However, the presence of $\mathrm{Au}$ nanoparticles in the films was confirmed using EDX analysis (Figure 4). This may be due to the fact that $\mathrm{Au}$ nanoparticles can enter the crystal lattice of $\mathrm{CuO}$.

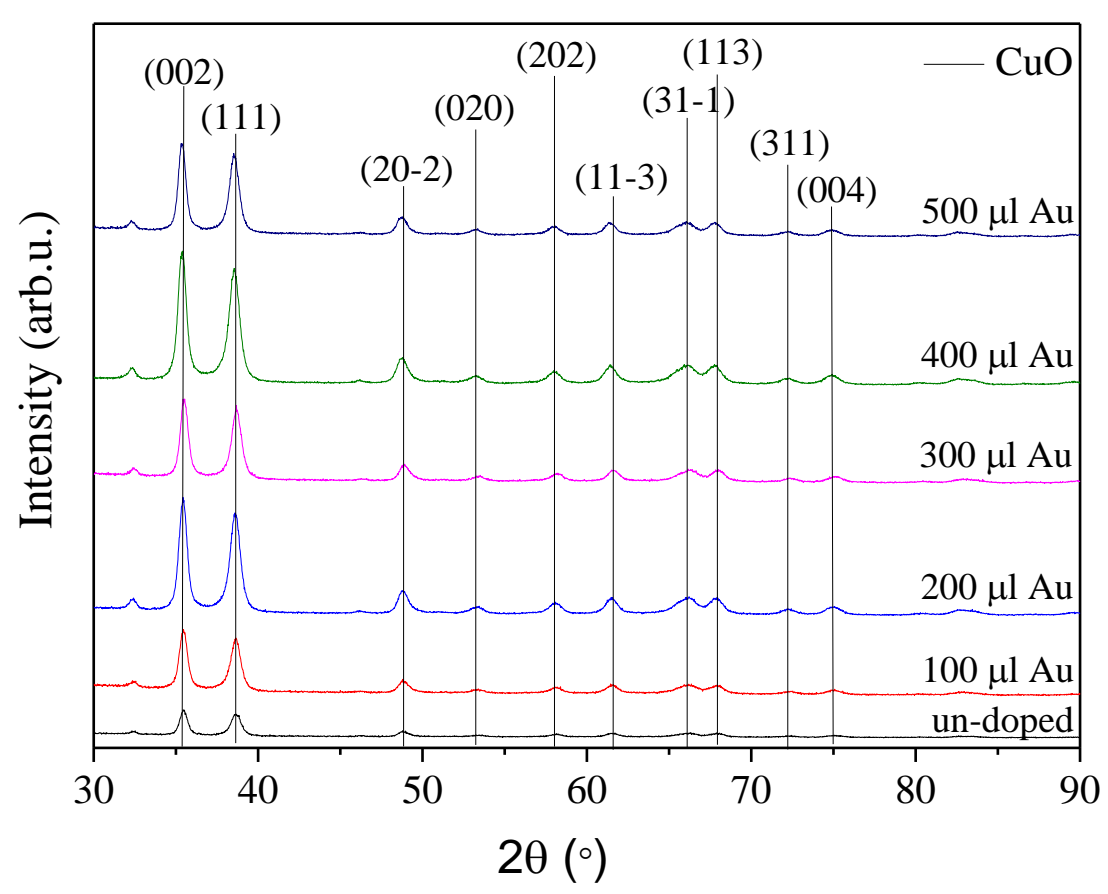

Figure 1. XRD patterns of $\mathrm{Au}-\mathrm{CuO}$ films

The average crystallite size was calculated with the Scherrer formula (Equation (1))

$D=\frac{0.9 \lambda}{\beta \cos \theta}$,

where $\lambda$ is the $\mathrm{X}$-ray wavelength $(\lambda=1.5405 \AA), \beta$ is the angular width at half maximum intensity (FWHM) of the peak, $\theta$ is the Bragg angle [21]. The crystal size of films changed between $151.61 \mathrm{~nm}$ to $157.59 \mathrm{~nm}$. To determine the preferred orientation of crystalline planes, the texture coefficients TC (hkl) are calculated using the Harris analysis technique (Equation (2)) [21]

$T_{c(h k l)}=\frac{I_{(h k l)} / I_{o(h k l)}}{1 / N \sum_{n} I_{(h k l)} / I_{o(h k l)}}$, 
where $\mathrm{T}_{\mathrm{c}(h k l)}$ is the texture coefficient of $(h k l)$ plane, $\mathrm{I}_{(h k l)}$ is the intensity measured for $(h k l)$ plane, $\mathrm{I}_{\mathrm{o}(h k l)}$ is the intensity of $(h k l)$ plane taken from standard data in PDF cart agreement in the X-ray diffraction pattern of material, $N$ is total reflection number, $n$ is diffraction peak number. The texture coefficient of the films has an orientation (002). The defective location density $(\delta)$ which gives the number of defects in the structure is calculated Equation (3) [21]

$\delta=\frac{1}{D^{2}}$.

The low value of the defective location density shows crystallized well. The micro-strain of films $(\varepsilon)$ is determined Equation (4)

$\varepsilon=\frac{\beta \cos \theta}{4}$,

where $\beta$ the full-width half-maximum and $\theta$ the diffraction angle. Microstresses are caused by the ionic radius between the $\mathrm{Au}$ and $\mathrm{Cu}$ (Figure 2). It was found that the surface tension and the location density of the films were changed in this process (Figure 2).

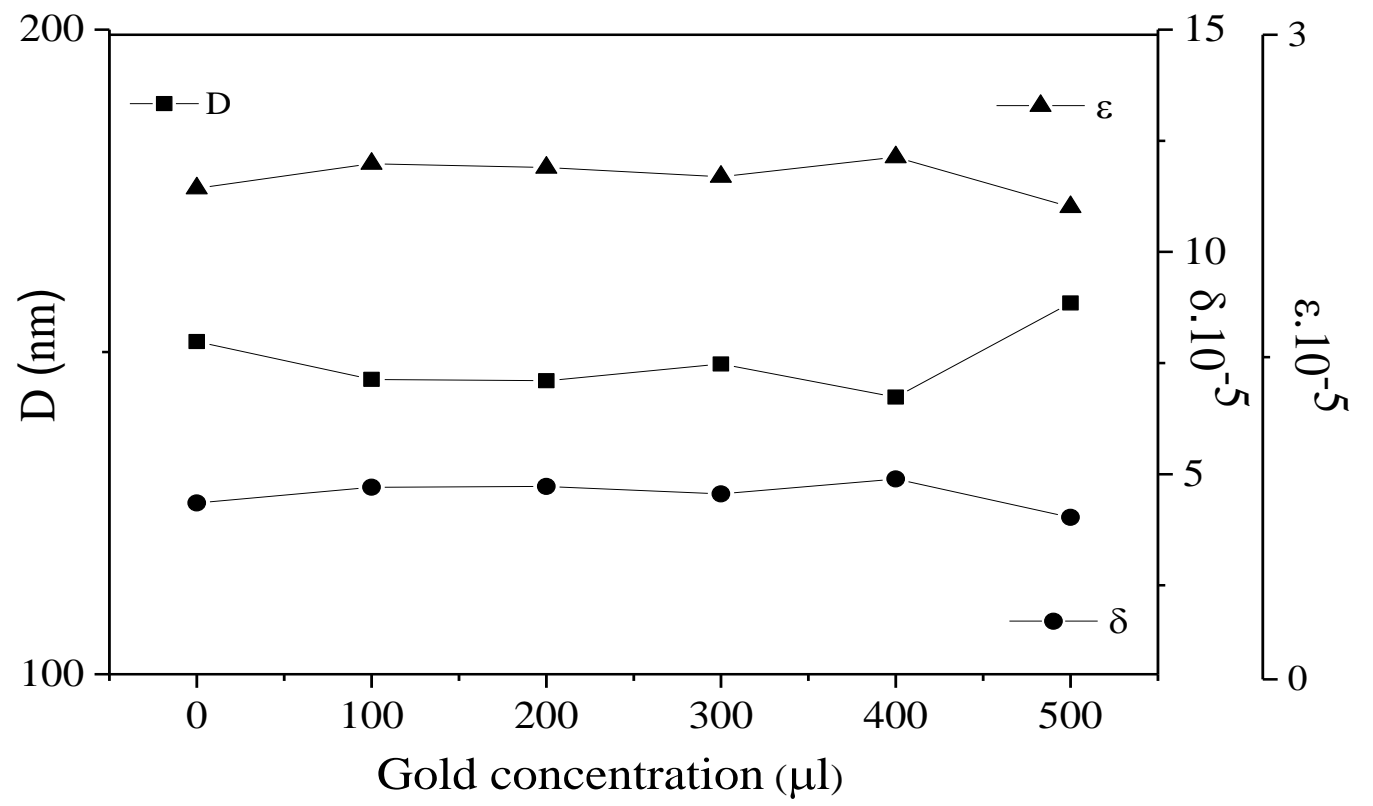

Figure 2. Variation of grain size, dislocation density, and micro-strain with respect to doping ratio of AuCuO films

The structural parameters of the Au-CuO films were shown in Table 1. 
Table 1. Structural parameters of $\mathrm{Au}-\mathrm{CuO}$ films

\begin{tabular}{|l|l|l|l|l|l|l|l|}
\hline Doped ratio $(\mu \mathrm{l})$ & $\mathrm{hkl}$ & $\mathrm{T}_{\mathrm{c}(111)}$ & $\mathrm{FWHM}\left({ }^{\circ}\right)$ & $\mathrm{D}(\mathrm{nm})$ & $\mathrm{E}$ & $\delta\left(\mathrm{nm}^{-2}\right)$ & $\mathrm{E}_{\mathrm{g}}(\mathrm{eV})$ \\
\hline 0 & $(002)$ & 1.761 & 0.550 & 151.612 & 2.285 & 4.350 & 1.66 \\
\hline 100 & $(002)$ & 1.803 & 0.572 & 145.750 & 2.400 & 4.705 & 1.72 \\
\hline 200 & $(002)$ & 1.891 & 0.573 & 145.517 & 2.381 & 4.722 & 1.75 \\
\hline 300 & $(002)$ & 1.938 & 0.563 & 148.128 & 2.339 & 4.557 & 1.79 \\
\hline 400 & $(002)$ & 1.876 & 0.583 & 142.999 & 2.430 & 4.890 & 1.86 \\
\hline 500 & $(002)$ & 1.780 & 0.529 & 157.587 & 2.198 & 4.026 & 2.09 \\
\hline
\end{tabular}

\subsection{Morphological Properties of Au-CuO Films}

The FESEM micrographs displayed in Figure 3 show the surface morphology and cross-section of annealed $\mathrm{Au}-\mathrm{CuO}$ films. The average film thickness was obtained from the cross-section images of the films. The thickness values changed as $0.879,1.084,1.126,1.392,2.631 \mu \mathrm{m}$, respectively (Figure 3). This could be an increase in the porosity. This porosity structure can be used to make gas sensor [22].

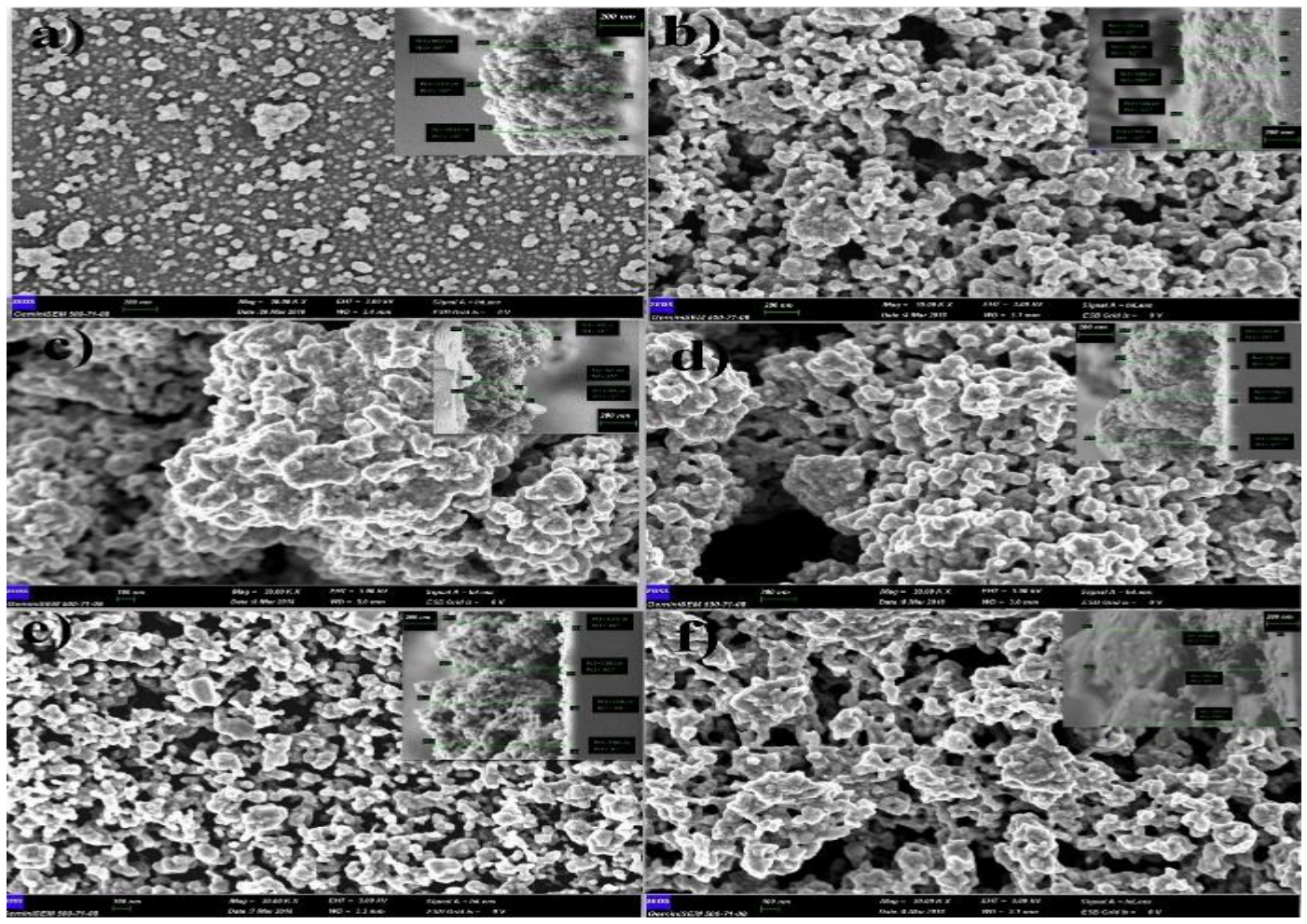

Figure 3. FESEM images of Au-CuO films a) $0 \mathrm{Au}$ b) $100 \mu \mathrm{ld}$ d) $200 \mu \mathrm{l} \mathrm{e)} 300 \mu \mathrm{lf}) 400 \mu \mathrm{lf)} 500 \mu \mathrm{l}$. The insets depict corresponding cross-section FESEM images

Energy-dispersive X-ray spectroscopy (EDX) analysis of the films is depicted in Figure 4. The EDX results display the essence of dopant Au element in the investigated sample. It was found that the atomic percentage increased with increasing Au concentration. 


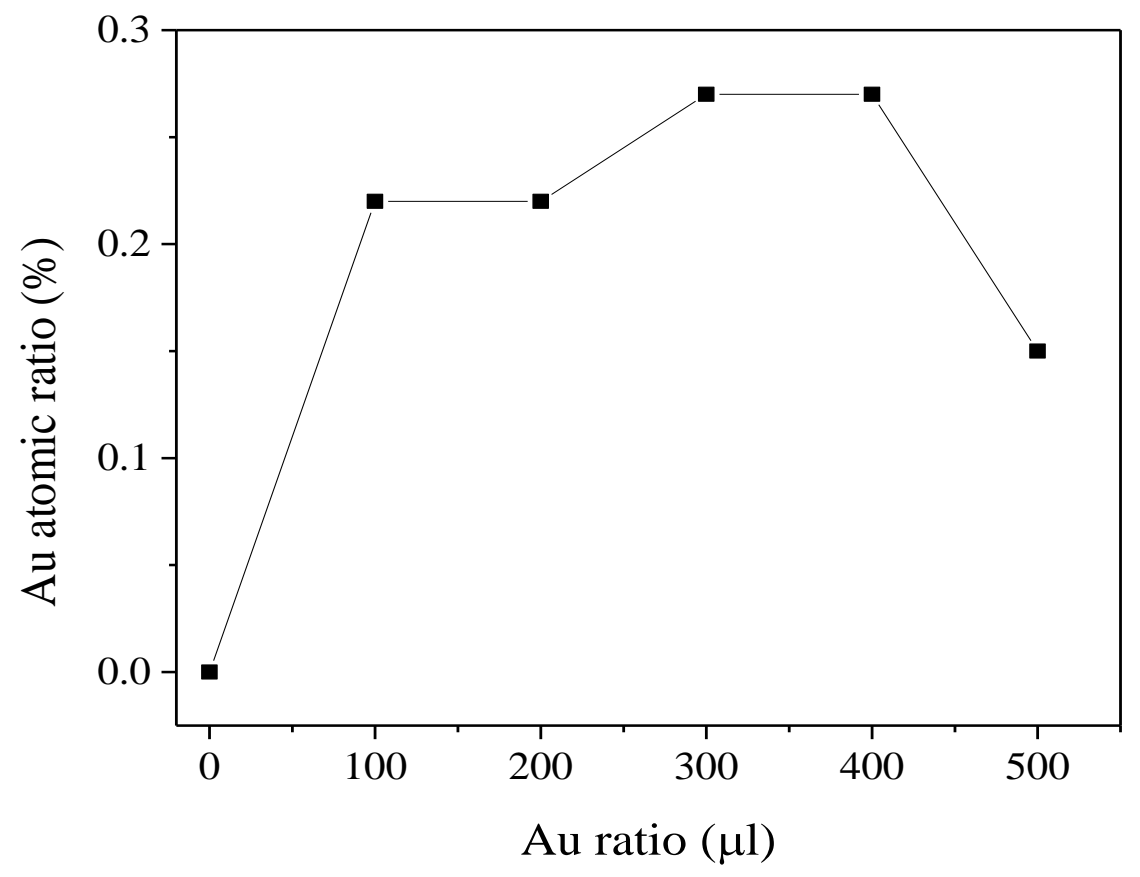

Figure 4. Variation of Au atomic ratio with respect to doping ratio of $\mathrm{Au}$-CuO films

\subsection{Electrical Properties of Au-CuO Films}

The home-made four probe method was used to estimate the resistivity of the films at room temperature. The changes in resistance of the films are shown in Figure 5. According to Figure 5, the resistivity of the films changed from 155.74 to $496.87 \Omega$.cm with annealing in $1 \mathrm{~h}$ at $500{ }^{\circ} \mathrm{C}$.

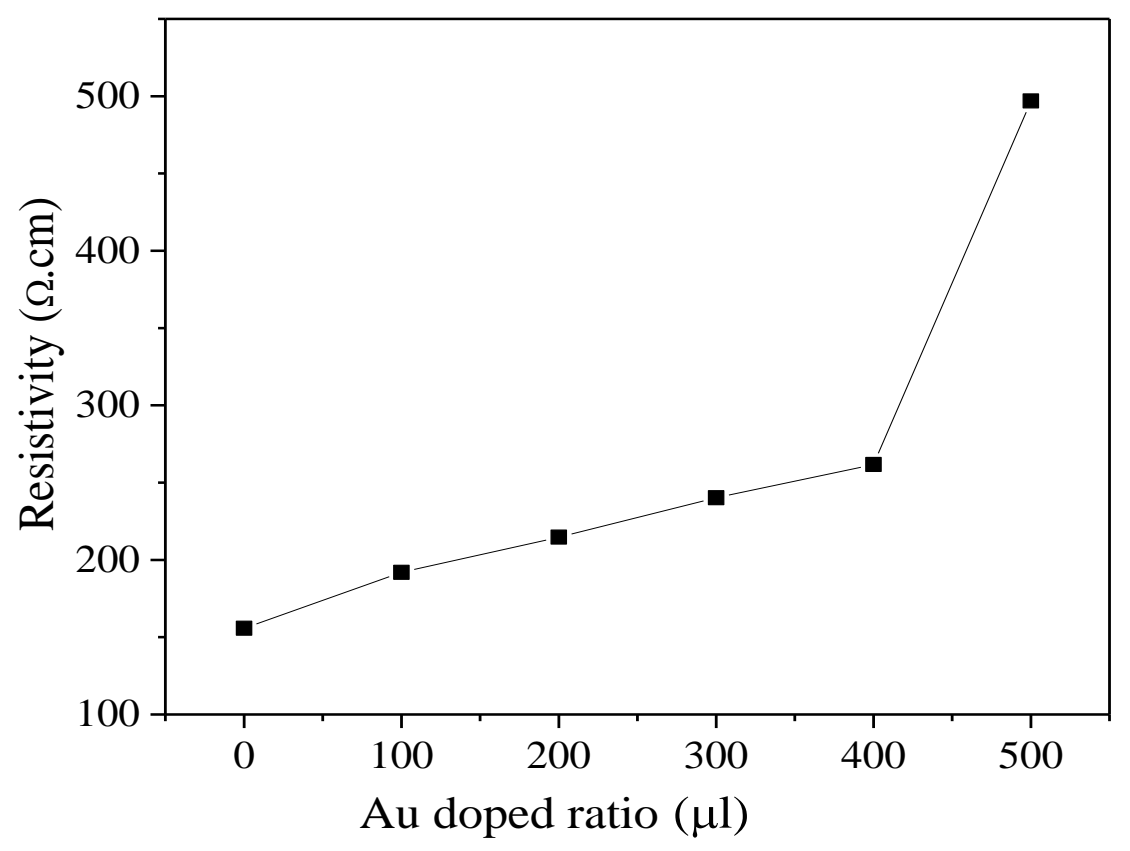

Figure 5. Variation of resistivity with respect to doping ratio of $\mathrm{Au}$-CuO films 


\subsection{Optical Properties of Au-CuO Films}

The optical transmittance of $\mathrm{Au}-\mathrm{CuO}$ films are shown in Figure 6. The transmittance pattern of the films is changing $9-35 \%$ at $700 \mathrm{~nm}$. The reason is that the thickness of films increased with increasing the $\mathrm{Au}$ doping ratio.

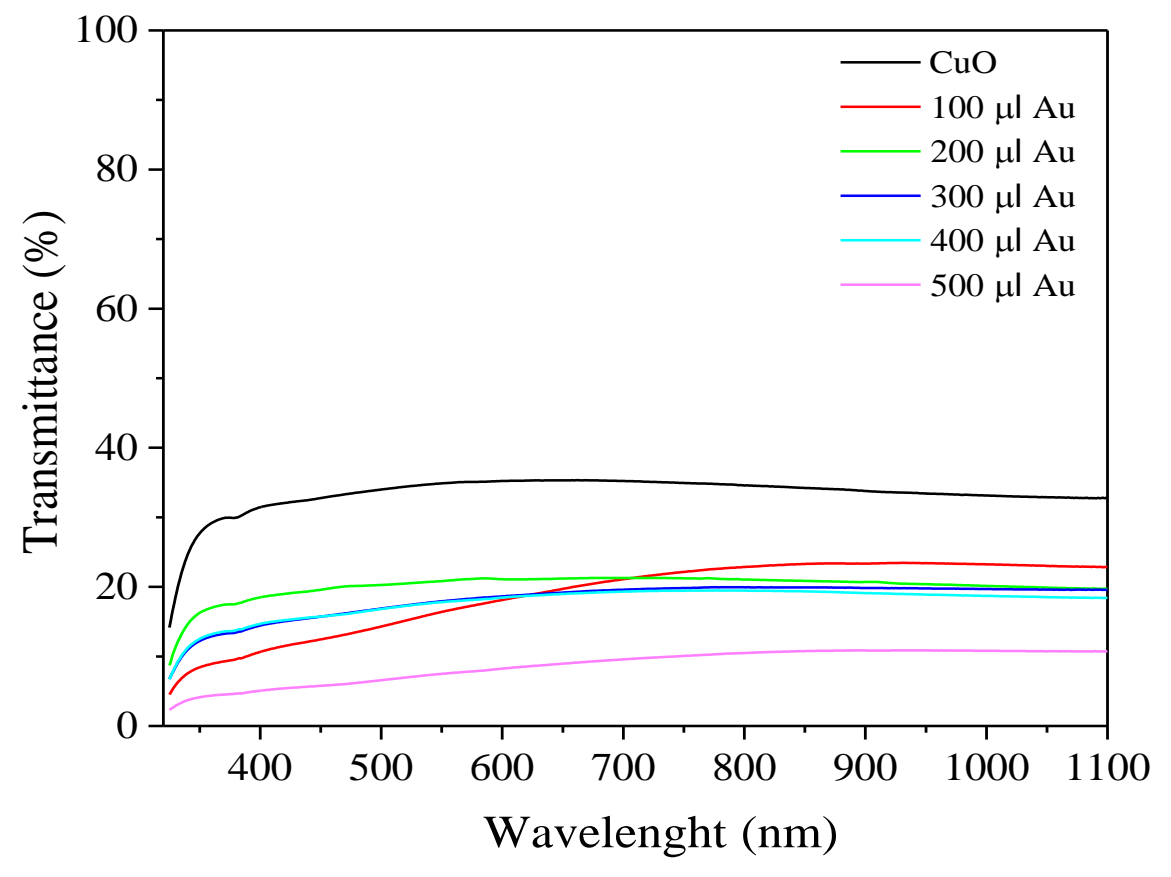

Figure 6. Transmittance spectra of $\mathrm{Au}-\mathrm{CuO}$ films

When the absorption pattern of the films examine, the absorption of the film was low in the UV region and relatively high in the visible region from the absorption spectrum (Figure 7). 


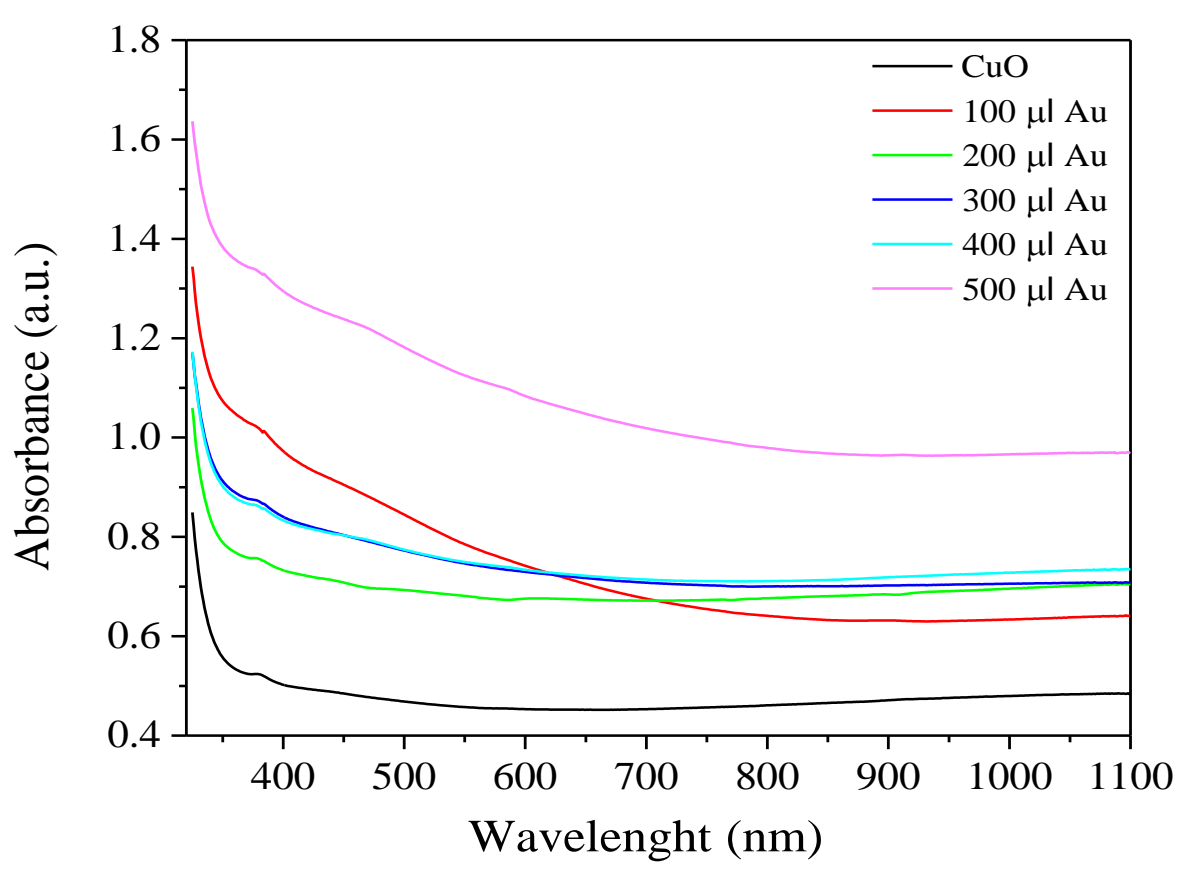

Figure 7. Absorbance spectra of $\mathrm{Au}-\mathrm{CuO}$ films

$\mathrm{T}$ and A data of the films were used to determine the reflection (R) of the film (Equation (5))

$T=(1-R)^{2} e^{-A}$,

where $\mathrm{R}$ is the reflectance, $\mathrm{A}$ is the absorbance [23]. The reflection spectrometer of the films depending on the wavelength is indicated in Figure 8. 


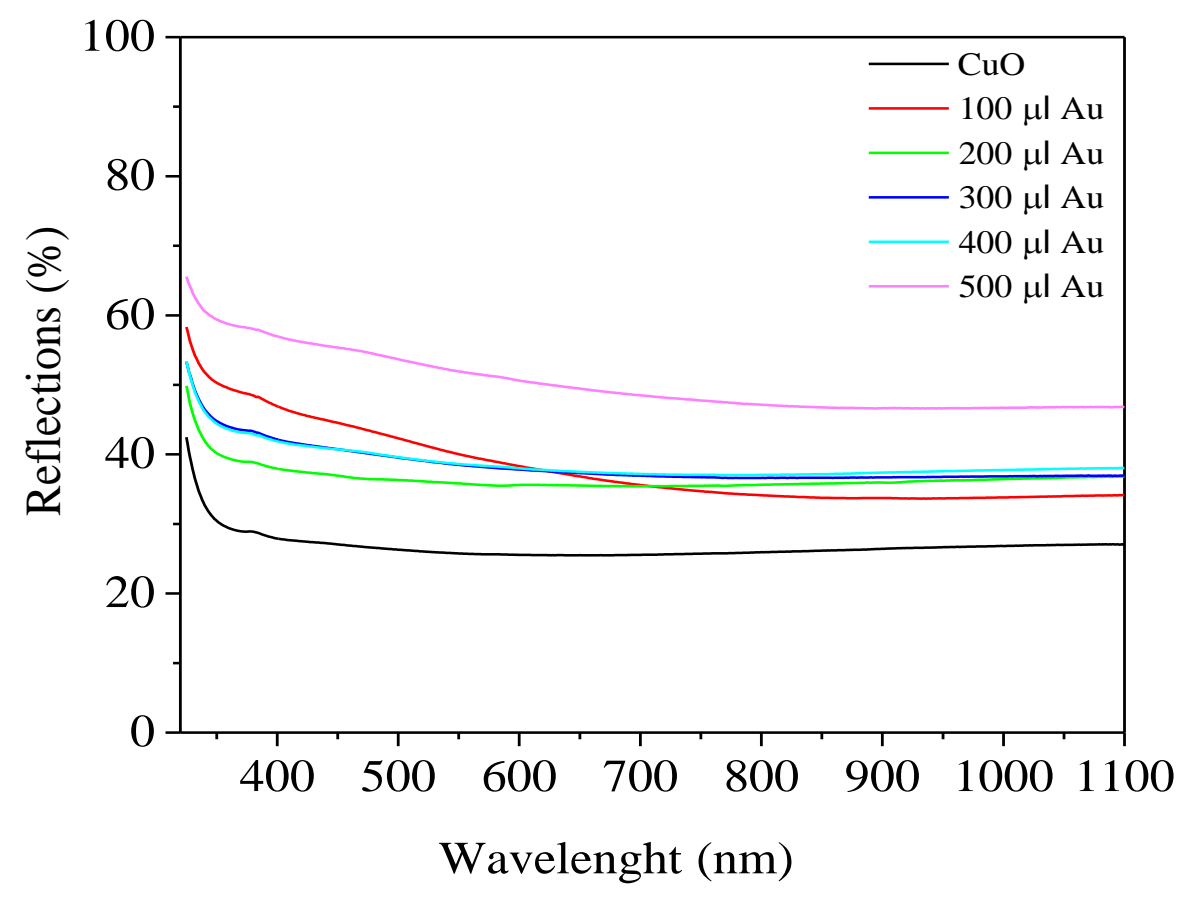

Figure 8. Reflection spectra of $\mathrm{Au}-\mathrm{CuO}$ films

The valences of the optical absorption coefficient $(\alpha)$ were calculated from Equation (6) [23]

$\alpha=\frac{A}{d}$,

where $\mathrm{d}$ is the film thickness and $\mathrm{A}$ is the optical absorbance value. A was used to estimate the direct energy band gap value of the film (Equation (7))

$(\alpha h v)^{2}=K\left(h v-E_{g}\right)$,

where $\mathrm{K}$ is a constant, $h v$ is photon energy and $\mathrm{Eg}$ is the band gap energy. In the films, the band gap varied between 1.86-2.09 eV and increased with doping ratio (Figure 9) [24]. 


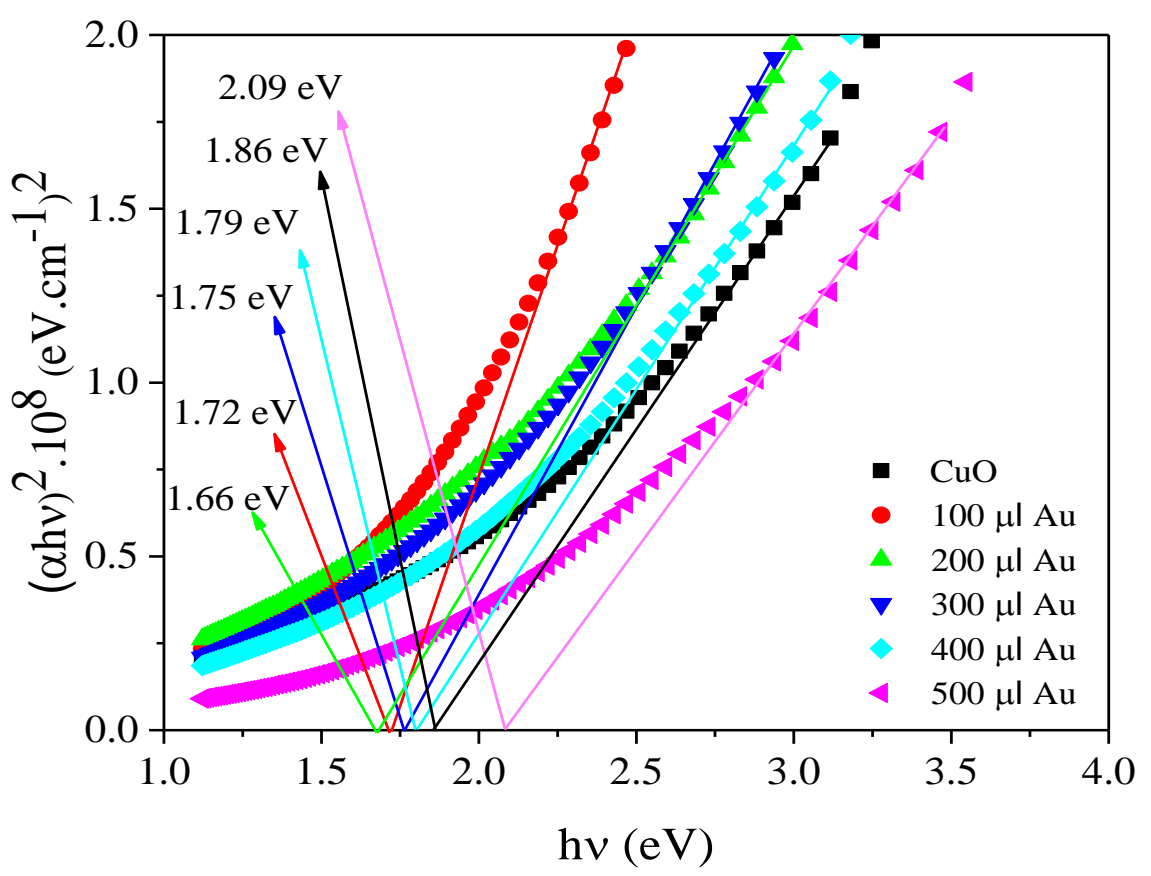

Figure 9. Plot of $(\alpha h v)^{2}$ versus photon energy curves of $\mathrm{Au}-\mathrm{CuO}$ films

The extinction coefficient $(\kappa)$ and refractive index (n) were also calculated using the data obtained from the optical spectrum. To determine $\kappa$ and $n$ we used Equation (8) [23]

$\kappa=\frac{\alpha \lambda}{4 \pi}$,

$n=\frac{1+R}{1-R}+\left[\frac{4 R}{(1-R)^{2}}-\kappa^{2}\right]^{1 / 2}$.

The extinction coefficient varied from 0.02 to 0.03 at $700 \mathrm{~nm}$ (Figure 10). 


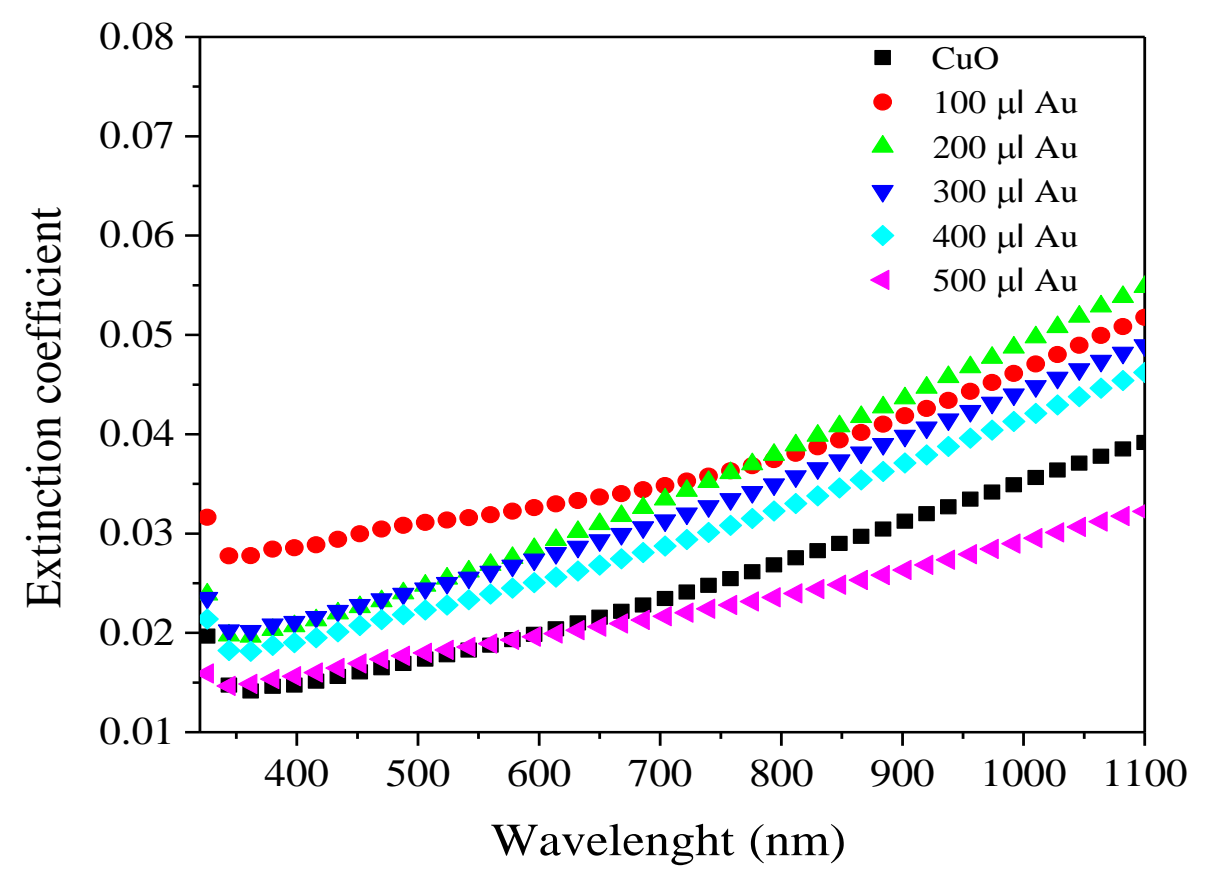

Figure 10. The diversity of extinction coefficient of $\mathrm{Au}-\mathrm{CuO}$ films with doping quantitative

For all of the films, the refractive index has a constant value between 500 and $1100 \mathrm{~nm}$, it reduced between 320 and $500 \mathrm{~nm}$ (Figure 11).

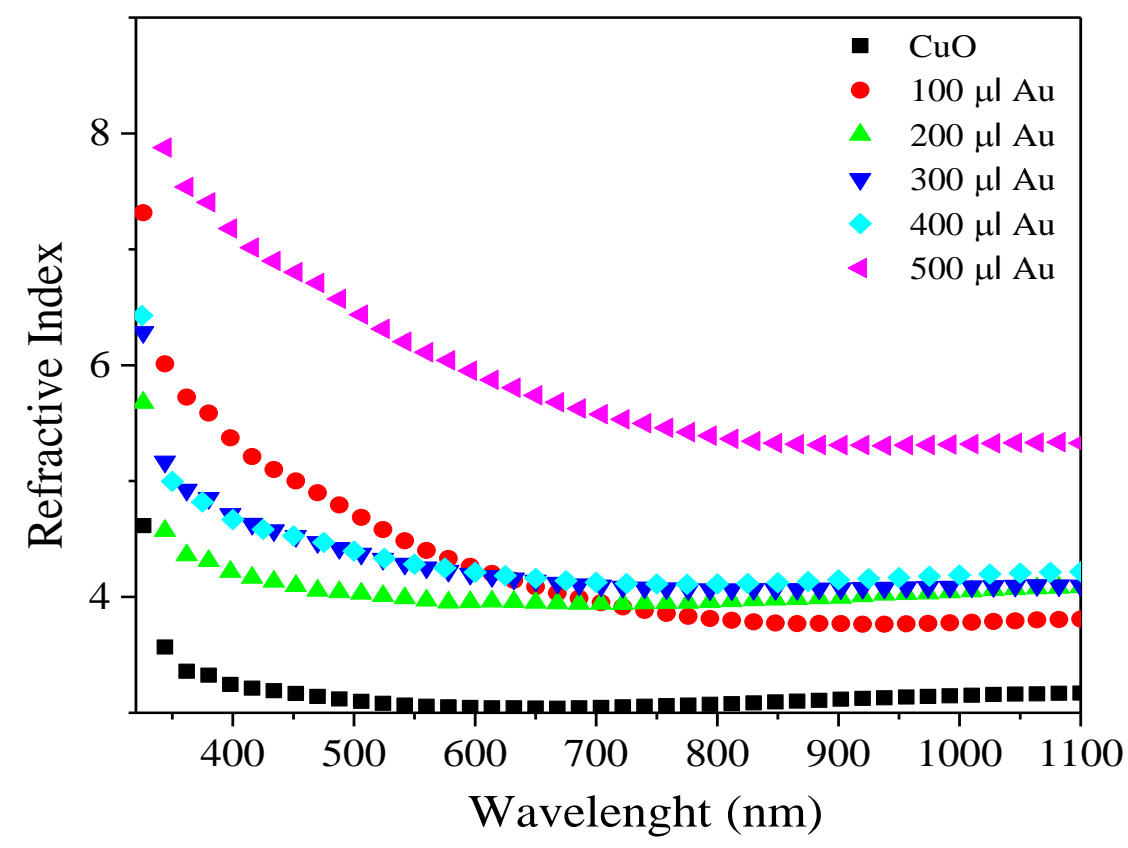

Figure 11. The diversity of refractive index of $\mathrm{Au}-\mathrm{CuO}$ films with doping quantitative 
The dielectric constants of the films were calculated via the data from the optical spectrum (Equations (10)(11)) $[8,26]$

$\varepsilon_{1}=n^{2}(\lambda)-\kappa^{2}$,

$\varepsilon_{2}=2 n(\lambda) \kappa(\lambda)$

The variation of $\varepsilon_{1}$ with wavelength is depicted in Figure 12. $\varepsilon_{1}$ values of all the films decreased with increasing wavelength.

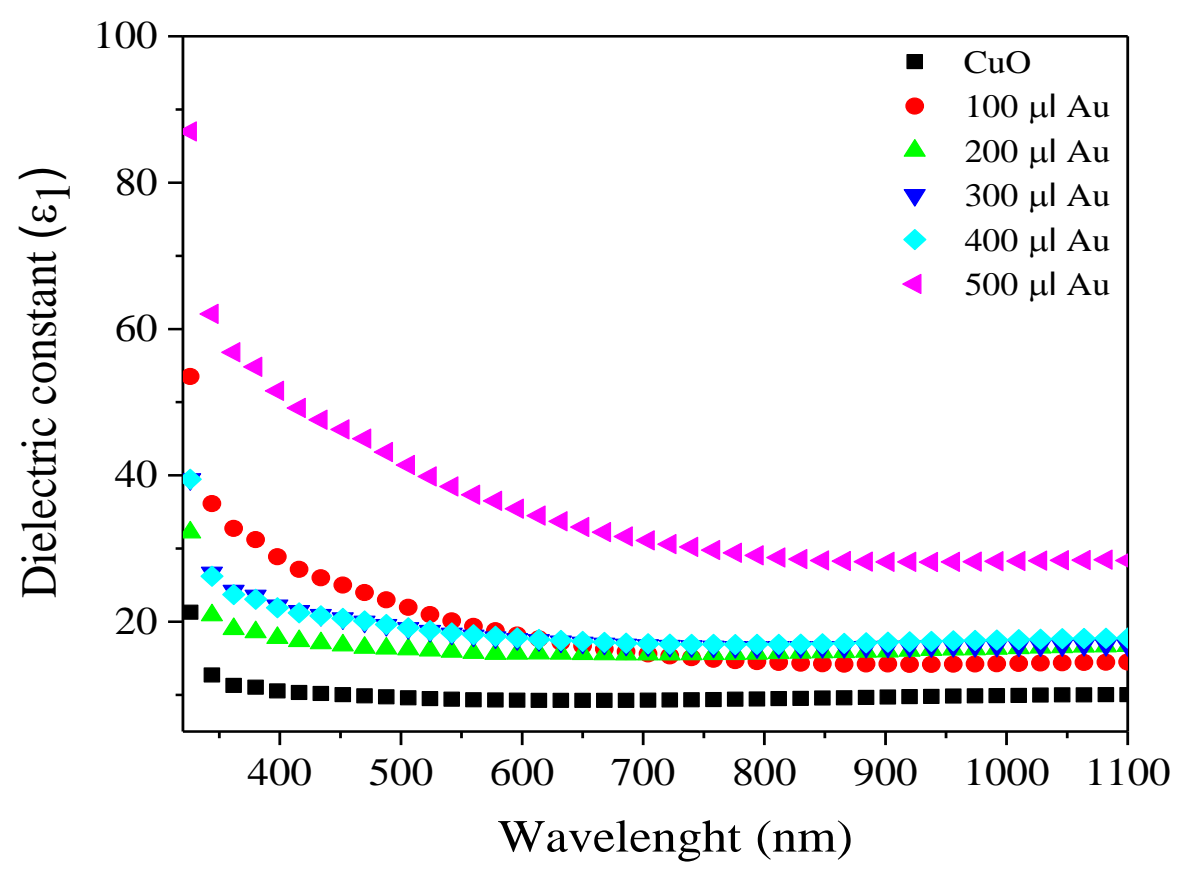

Figure 12. The diversity of dielectric coefficient $\left(\varepsilon_{1}\right)$ of $\mathrm{Au}-\mathrm{CuO}$ films with doping quantitative

Figure 13 shows the variation of the imaginary dielectric constant $\left(\varepsilon_{2}\right)$ with the wavelength. 


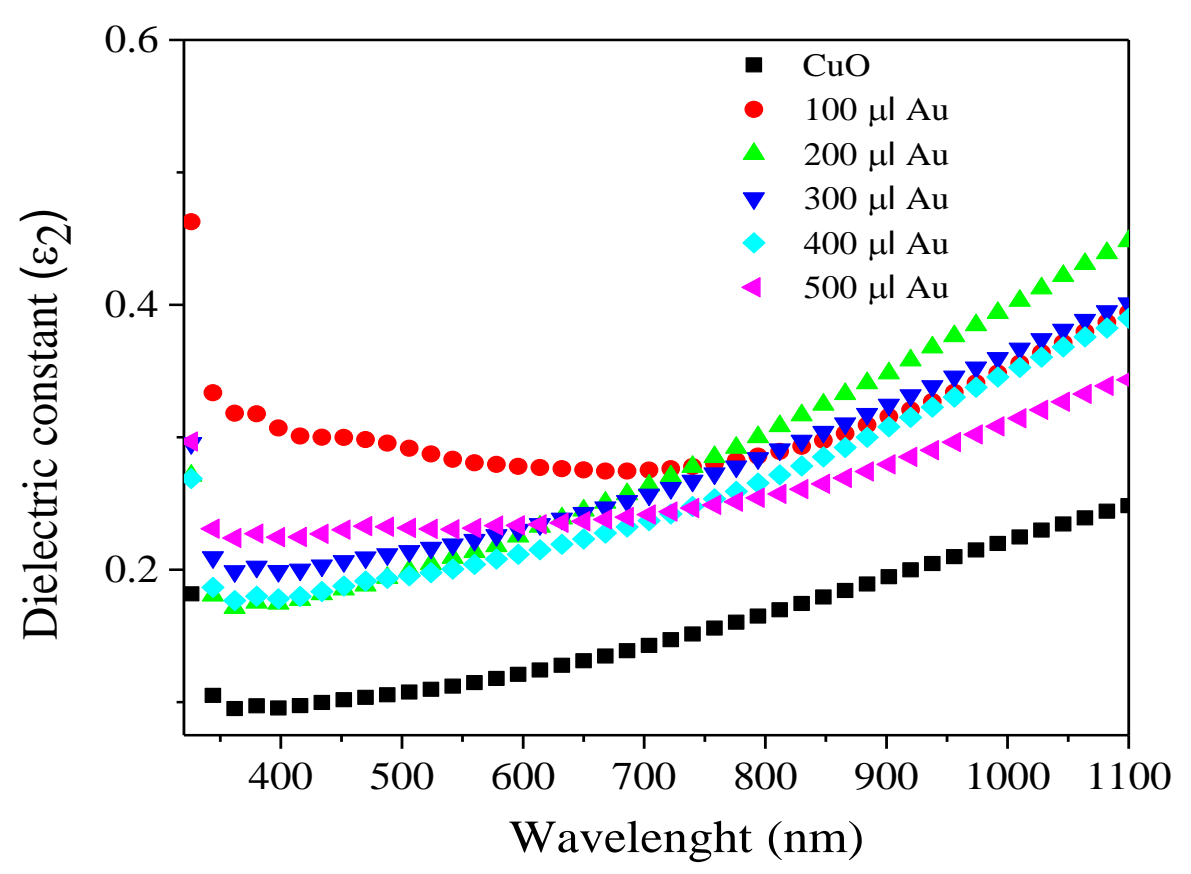

Figure 13. The diversity of dielectric coefficient ( $\left.\varepsilon_{2}\right)$ of $\mathrm{Au}$-CuO films with doping quantitative

\section{CONCLUSIONS}

In this study, $\mathrm{Au}-\mathrm{CuO}$ films produced by $\mathrm{CBD}$ method were annealed at $500{ }^{\circ} \mathrm{C}$ in 1 hour. $\mathrm{XRD}$ analysis studies show that the $\mathrm{CuO}$ phase in the monoclinic structure was detected in the annealed films but there was no Au peak in this film. In the FESEM images, it was determined that the surface structure changed. The resistance of the films obtained by the four-probe method was changed by annealing (155.74-496.87) processes. All films obtained have a higher absorption in the IR region. The energy band gap varied between $1.86-2.09 \mathrm{eV}$ for the films. According to this work, $\mathrm{Au}-\mathrm{CuO}$ films can be structurally, electrically and optically modified by annealing.

\section{ACKNOWLEDGEMENTS}

The part of this work was supported by the Scientific Research Project Commission of Erciyes University to support my work under Projects No.FCD-2016-6744.

\section{CONFLICTS OF INTEREST}

No conflict of interest was declared by the author.

\section{REFERENCES}

[1] Guillen, C., Herrero, J., "Single-phase $\mathrm{Cu}_{2} \mathrm{O}$ and $\mathrm{CuO}$ thin films obtained by low-temperature oxidation processes", J. Alloy. Compd., 737: 718-724, (2018).

[2] Akaltun, Y., "Effect of thickness on the structural and optical properties of $\mathrm{CuO}$ thin films grown by successive ionic layer adsorption and reaction", Thin Solid Films, 594: 30-34, (2015). 
[3] Ghamdi, A., Khedr, M., Ansari, M., Hasan, P., Abdel-wahab, M., Farghali, A., "RF sputtered CuO thin films: Structural, optical and photo-catalytic behavior", Physica E, 81: 83-90, (2016).

[4] Samarasekara, P., Kumara, N., Yapa, N., "Sputtered copper oxide (CuO) thin films for gas sensor devices", J. Phys.: Condens. Matter., 18: 2417-2420, (2006).

[5] Wijesundera, $\mathrm{P}$., "Fabrication of the $\mathrm{CuO} / \mathrm{Cu} 2 \mathrm{O}$ heterojunction using an electrodeposition technique for solar cell applications", Semicond. Sci. Technol., 25: 045015, (2010).

[6] Moralesa, J., Sancheza, L., Martın, F., Barradob, J., Sanchez, M., "Nanostructured CuO thin film electrodes prepared by spray pyrolysis: a simple method for enhancing the electrochemical performance of $\mathrm{CuO}$ in lithium cells", Electrochim. Acta, 49: 4589-4597, (2004).

[7] Ghamdi, A., Khedr, M., Ansari, M., Hasan, P., Abdel-wahab, M., Farghali, A., "RF sputtered CuO thin films: Structural, optical and photo-catalytic behavior", Physica E, 81: 83-90, (2016).

[8] Moumen, A., Hartiti, B., Thevenin, P., Siadat, M., "Synthesis and characterization of CuO thin films grown by chemical spray pyrolysis", Opt. Quant. Electron, 49 (70): 2-17, (2017).

[9] Othmane, D., Qachaou, Y., Raidou, A., Nouneh, K., Lharch, M., Fahoume, M., "Study of the physical properties of $\mathrm{CuO}$ thin films grown by modified SILAR method for solar cells applications", Superlattices Microstruct., 127: 93-99, (2019).

[10] Nair, M., Guerrero, L., Arenas, O., Nair, P., "Chemically deposited copper oxide thin films: Structural, optical and electrical characteristics”, Appl. Surf. Sci., 150: 143-151, (1999).

[11] Bai, R., Chaudhary, S., Pandya, D., "Temperature dependent charge transport mechanisms in highly crystalline p-PbS cubic nanocrystals grown by chemical bath deposition", Mater. Sci. Semicond. Process., 75: 301-310, (2018).

[12] Ahmed, M., Mwankemwa, B., Carleschi, E., Doyle, B., Meyer, W., Nel, J., "Effect of Sm doping $\mathrm{ZnO}$ nanorods on structural optical and electrical properties of Schottky diodes prepared by chemical bath deposition", Mater. Sci. Semicond. Process., 79: 53-60, (2018).

[13] Marzukil, M., Zain, M., Hisham, N., Zainon, N., Harun, A., Ahmad, R., “Annealing effects on the formation of copper oxide thin films", IOP Conf. Series: Mat. Sci. Eng., 318: 012060, (2018).

[14] Gopalakrishna, D., Vijayalakshmin, K., Ravidhas, C., "Effect of annealing on the properties of nanostructured $\mathrm{CuO}$ thin films for enhanced ethanol sensitivity", Ceram. Int., 39: 7685-7691, (2013).

[15] Saravanan, V., Shankar, P., Mani, G., Rayappan, J., "Growth and characterization of spray pyrolysis deposited copper oxide thin films: Influence of substrate and annealing temperatures", J. Anal. Appl. Pyrolysis, 111: 272-277, (2015).

[16] Rydosz, A., Szkudlarek, A., "Gas-sensing performance of Mn-doped CuO-based thin films working at different temperatures upon exposure to propane", Sensor, 15: 20069-20085, (2015).

[17] Shaikha, J., Pawara, R., Devan, R., Ma, Y., Salvi, P., Kolekar, S., Patil, P.S., "Synthesis and characterization of $\mathrm{Ru}$ doped $\mathrm{CuO}$ thin films for supercapacitor based on bronsted acidic ionic liquid", Electrochim. Acta, 56: 2127-2134, (2011).

[18] Zhao, F., Qiu, H., Pan, L., Zhu, H., Zhang, Y., Guo, Z., Yin, J., Zhao, X., Xiao, J., "Ferromagnetism analysis of Mn-doped CuO thin films", J. Phys. Condens. Matter., 20: 425208, 1-5, (2008).

[19] Ando, M., Kobayashi, T., Iijima, S., Haruta, M., "Optical CO sensitivity of Au-CuO composite film by use of the plasmon absorption change", Sens. Actuators B, 96: 589-595, (2003). 
[20] Proença, M., Borges, J., Rodrigues, M., Domingues, R., Dias, J., Trigueiro, J., Bundaleski, N., Teodoro, O., Vaz, F., "Development of $\mathrm{Au} / \mathrm{CuO}$ nanoplasmonic thin films for sensing applications", Surf. Coat. Techn., 343: 178-185, (2018).

[21] Prabua, R., Valanarasua, S., Ganesh, V., Shkir, M., AlFaify, S., Kathalingam, A., Srikumare, S., Chandramohan, R., "An effect of temperature on structural, optical, photoluminescence and electrical properties of copper oxide thin films deposited by nebulizer spray pyrolysis technique", Mater. Sci. Semicond. Process., 74: 129-135, (2018).

[22] Proença, M., Borges, J., Rodrigues, M., Domingues, R., Dias, J., Trigueiro, J., Bundaleski, N., Teodoro, O., Vaz, F., "Development of $\mathrm{Au} / \mathrm{CuO}$ nanoplasmonic thin films for sensing applications", Surf. Coat. Techn., 343: 178-185, (2018).

[23] Güneri, E., Kariper, A., "Characterization of high quality chalcogenide thin film fabricated by chemical bath deposition”, Electron. Mater. Lett., 9(1):13-17, (2013).

[24] Ray, S., "Preparation of copper oxide thin film by the sol-gel-like dip technique and study of their structural and optical properties", Sol. Energy Mater. Sol. Cells, 68: 307-312, (2001).

[25] Dhanasekaran, V., Mahalingam, T., Chandramohan, R., Rhee, J., Chu, J.P., "Electrochemical deposition and characterization of cupric oxide thin films", Thin Solid Films, 520: 6608-6613, (2012). 